\title{
A recepção da exposição de Arte Incomum e o problema da duração dos julgamentos artísticos
}

\author{
ARLEY ANDRIOLO
}

\section{Resumo}

O termo “Arte Incomum”, criado no Brasil em 1981, pleiteava a formação de um campo para as obras inventivas produzidas por membros das classes populares no Brasil, ampliando o conceito francês de "arte bruta". No entanto, o termo não foi muito usado pela crítica. Por meio de uma análise psicossocial da primeira exposição de Arte Incomum, podese compreender que o problema está na historicidade dos julgamentos artísticos constituídos no Brasil desde a década de 1950. Estes concebiam apenas duas categorias para as criações populares: "arte ingênua" e "arte psicopatológica".

Palavras-chave:

Arte Bruta, história da arte (século XX), recepção estética 


\title{
The reception of the "Arte Incomum" exhibition and the problem of artistic judgments duration
}

\author{
ARLEY ANDRIOLO
}

\begin{abstract}
The term "Arte Incomum", created in Brazil in 1981, proposed the formation of a field for inventive works of art produced by members of the popular classes in Brazil, extending the French concept of "Art Brut". However, the term has no longer used by the critics. Through a psychosocial analysis of the first exhibition of Arte Incomum in Brazil one can comprehends that the problem is done by the historicity of artistic judgments made in Brazil since the 1950s. These judgments conceived only two categories for popular
\end{abstract}




\section{Introdução}

Sob a curadoria geral de Walter Zanini, a XVI Bienal de São Paulo estava marcada pela busca de renovação da sua própria estrutura: depois de trinta anos, não seria mais organizada por países, mas por tendências, como anunciava a imprensa da época. Tinham-na também como enigmática, devido ao silêncio dos organizadores, e, também, por causa de novidades tais como um módulo dedicado à "Arte Incomum".

Em julho de 1981, circulava na imprensa brasileira a notícia. A jornalista Leonor Amarante (1981a, p. 39) perguntou a Walter Zanini sobre o significado da designação Arte Incomum e constatou que se tratava de "toda a linguagem que se mantém distante da arte erudita e que também é distinta de toda a produção considerada popular". À medida que se aproximava a inauguração, formava-se uma ideia mais precisa, como se observa na revista Projeto (set. 1981, p. 10):

Diferente da 'arte popular' e da 'arte primitiva', apesar de ser em boa parte fruto de criadores que não tiveram nenhuma aprendizagem artística formal, a 'Arte Incomum' traz obras de artistas que criaram a partir de visões próprias, às vezes através de sonhos.

Na apresentação do módulo de Arte Incomum, Zanini (1981, p. 7) esclarece seu objetivo em "despertar de forma ampla a atenção do público para a produção altamente criativa, à margem do sistema da arte cultural, assim como trazer incentivo à sua pesquisa e preservação no meio brasileiro". Reconhece os limites da coleta de exemplares, mas afirma a preciosidade dessas "cosmogonias absolutamente pessoais". Enfim, entendia-se Arte Incomum como "múl- 
tiplas manifestações individuais da espontaneidade de invenção não-redutíveis a princípios culturais estabelecidos".

A referência a Jean Dubuffet é explícita; particularmente, Zanini dizia basear-se no catálogo de uma exposição de Art Brut da década de 196o. Além disso, traduziu-se um escrito do artista francês intitulado "Lugar ao incivismo" junto aos textos do catálogo. Não obstante, implicitamente o próprio curador da Bienal procura afastar-se da ortodoxa definição de Dubuffet e sua ciosa "escolha determinada", dizendo que a Bienal "conectou uma produção de ordem diversificada" (Zanini, 1981, p. 7).

Este artigo objetiva descrever o processo de recepção daquela exposição, em particular, examinando as manifestações publicadas na imprensa brasileira. Um conjunto importante de documentos foi consultado no acervo da Fundação Bienal de São Paulo, sobre o qual se procedeu a um exame de artigos, notas de jornais e revistas de divulgação. $\mathrm{O}$ exame das fontes primárias conduz a dados organizados em série, cuja observação possibilita notar quais categorias emergem para a pesquisa. Para a compreensão do problema, essas categorias são projetadas em uma rede de significados estruturada tanto pela história da arte quanto pelas formas de perceber. Notadamente, o processo histórico mostra o reconhecimento social das obras plásticas populares pelo campo artístico ao longo do século XX.

\section{A invenção da Art Brut}

Primeiramente, cabe identificar a formação do conceito Art Brut, fundamento da exposição de Arte Incomum. A origem dessa história pode ser localizada nas viagens de Jean Dubuffet, sobretudo à Suíça, onde conheceu as obras fantásticas de artistas internados, tais como Adolf Wölfli, Aloïse, Anton Müller e o conhecido "prisioneiro de Bale" (Joseph Giavarini), em cidades como Lausanne, Berna e Bale. As visitas aos hospitais psiquiátricos abriram-lhe as brechas para um novo projeto: coletar obras de uma "arte outra" e publicar uma série de cadernos a esse respeito.

Em Lausanne, julho de 1945, o artista francês recebeu de presente de Paul Budry o importante livro de Hans Prinzhorn sobre a "expressão artística dos loucos" e, com René Auberjonois, foi ao vilarejo de Ballaigues visitar Louis Soutter, um primo humilde do famoso arquiteto Le Corbusier, dedicado a realizar desenhos em tinta preta com as pontas dos dedos (Peiry, 1997). Em setembro, estava em Rodez, sul da França, onde conheceu Gaston Ferdière, médico que acompanhava o tratamento de Antonin Artaud 
e travou contato com as pinturas de Guillaume Pujolle, antes de partir para Lozère, em visita ao hospital psiquiátrico de Saint-Alban-sur-Limagnole. Neste, surpreendeu-se com as esculturas de Auguste Forestier, cuja obra tematizava fábulas ou personalidades nacionais. Em Genebra, o encontro com o dr. Charles Ladame resultou na formação de um dos núcleos da Colection de l’Art Brut, também encantou-se com as máscaras populares do Lötschental, expostas no Museu de Etnografia. Conforme assinalou Peiry (1997, p. 11), o nome Art Brut apareceu pela primeira vez numa carta de Dubuffet para Auberjonois, datada de 28 de agosto de 1945 .

Desde então, estava em curso um projeto, naqueles anos manifesto principalmente pela tentativa de coletar peças e publicar alguns cadernos apresentando os criadores marginais. Tais cadernos seriam organizados por Dubuffet e reuniriam escritos de vários autores, numa edição a ser realizada por Gaston Gallimard. Não obstante tal projeto ter sido protelado, o empreendimento tomou corpo e angariou novos colaboradores, possibilitando a inauguração do Foyer de l'Art Brut, em novembro de 1947, ocupando o subsolo da galeria René Drouin (Place Vendôme, Paris). O grupo reunia, entre outros, Jean Paulhan, George Limbour, Michel Tapié, André Breton, Charles Ratton, Henri-Pierre Roché, Edmond Bomsel, implicados no intuito de favorecer e desenvolver as pesquisas de obras brutas.

Essa primeira aparição da coleção de Art Brut fortaleceu o campo aberto pelas vanguardas históricas, com Max Ernst e Paul Klee, entre outros artistas, que haviam adentrado os ambientes sombrios dos hospitais psiquiátricos no intuito de desvendarem os processos criativos básicos. Com a retomada desse ideal vanguardista, Dubuffet não apenas o prolonga, mas o circunscreve e, sobretudo, o retira do domínio das teorias psicopatológicas. Além disso, a proposta do artista francês previa também procedimentos específicos de exposição das obras. Convém lembrar que Dubuffet cultivava um discurso acerca do confidencial, da clandestinidade e das linguagens implícitas. Ao mesmo tempo em que se esquivava da tarefa de dizer claramente o que era essa obra bruta, afirmando que o ato de nomear era quase decretar a morte das coisas, elaborou regras de exposição e controle da coleção. Em síntese, sua contribuição foi decisiva ao estabelecer novas formas de olhar as obras plásticas mais inventivas de criadores oriundos das classes populares.

No dia 11 de outubro de 1948, fundou-se em Paris a Compagnie de l'Art Brut. O Foyer foi transferido para um pequeno pavilhão emprestado por Gaston Gallimard, na Rue de 
l'Université. A empreitada não durou muito e, em julho de 1951, Dubuffet propõe a sua dissolução, efetivada em 23 de janeiro do ano seguinte. Quando seu fundador aceitou o convite de Afonso Ossorio de levar a coleção consigo para os Estados Unidos, ela contava com cerca de $\mathbf{1 . 2 0 0}$ obras; os dois artistas haviam se conhecido em Paris, em 1949, por intermédio de Jackson Pollock. Em abril de 1952, Dubuffet volta para a França, enquanto a coleção retornaria apenas 1962. Não encontrando as condições esperadas em terras francesas, decide pela doação do acervo à municipalidade de Lausanne, na Suíça, em 13 de julho de 1971. Tratava-se de um acordo que obrigava a constituição de um museu unicamente dedicado à coleção de arte bruta que contava, então, com cerca de 6.500 peças de mais de 100 criadores, no qual a conservação, integridade e continuidade das pesquisas ficariam a cargo de Michel Thévoz.

À formação da coleção conjugou-se um processo de orientação da percepção sobre tais obras. Para se entender esse processo, será necessário resumidamente apresentar três aspectos constituintes da formulação de Dubuffet, capazes de definir minimamente Art Brut: a ideia de arte, de artista e de obra.

Primeiramente, cabe notar que Dubuffet distinguia os processos artísticos dos racionais no conhecimento. "A arte é um outro meio de conhecimento, no qual as vias são outras: são aquelas da vidência [voyance]" (DUBUFFET, 1999, p. 89). Além disso, desde pelo menos 1947, o artista francês considerava duas ordens estéticas: de um lado estava a arte cultural, a qual, independentemente do nome que receba (clássica, barroca, etc.), é sempre a mesma; de outro, estava l'Art Brut, arte "selvagem e furtiva como uma cerva" (p. 83). Dois anos depois, no catálogo da primeira exposição de sua coleção, o artista francês precisava suas ideias num prefácio intitulado "L’Art Brut préféré aux arts culturels", no qual registrou: "A verdadeira arte está sempre lá onde não se espera. Lá onde ninguém pensa nela nem pronuncia seu nome" (DUBUFFET, 1999, p. 90).

O criador do conceito de Art Brut não admitia a conjugação de sua coleção com obras da chamada "arte cultural", sustentando por muitos anos certa clandestinidade da própria coleção, evitando empréstimos e exposições em que suspeitasse de qualquer aproximação com obras profissionais. Era mesmo uma visão idealista de arte que permitiu ao artista desenvolver seu projeto, mas que foi por ele próprio revista depois, quando passou a considerar a Art Brut não como uma coisa em si, mas um pólo, oposto ao da arte cultural.

Em segundo lugar, a noção de "artista bruto" teve relação 
com o interesse de Dubuffet pelo homem comum. Essa é uma figura central no seu pensamento, tendo a expressão l'homme du commun sido utilizada primeiramente em 1944, conforme Peiry (1997, p. 267), em carta a Jean Paulhan. Por meio desta ideia referia-se às pessoas simples e sem instrução o "homem de rua”. Este interesse do artista pelas classes populares e pela vida cotidiana, suscitou, por exemplo, a série Métro, de 1943, numa época em que percorria os bairros populares de Paris e projetava um guia sobre esses lugares.

Desta valorização do homem comum deriva sua crítica às noções de gênio artístico e dom excepcional, as quais distinguem a arte como propriedade de poucos iluminados, e da radicalização no sentido dos criadores mais humildes, por ele designados "autores". Em 1947, escreveu que se tratava de pessoas impermeáveis à cultura artística, preservadas do mimetismo do meio cultural, que trabalham entregues a seu próprio encantamento e para si próprias, sem visar carreira, modos de exposição e reconhecimento de seu trabalho; "impulsionadas pela necessidade única de exteriorizar as festas que têm lugar em seu espírito" (DUBUFFET, 1999, p. 85). Para reconhecer um criador, partilha o homem comum circunscrevendo autores que escaparam aos condicionamentos culturais, ao conformismo social, sem formação artística, indiferentes à promoção comercial, cuja criação é solitária e clandestina, reveladores de uma forte tensão mental, totalmente livres e com pureza de expressão (Dubuffet, 1964; Thévoz, 1980; Peiry, 1997).

Nesse contexto, criador e criatura são inseparáveis. Os cadernos levados a público tinham por objetivo construir a história de vida daquelas pessoas obscuras, cujo processo criativo fora constantemente rechaçado pela cultura erudita. A apresentação nas tabuletas de suas biografias, sem diagnóstico no caso dos internos psiquiátricos, constando sempre a profissão, conferia-lhes sua humanidade e condição social.

Em terceiro lugar, no que concerne à obra bruta, Dubuffet (1999, p. 95) escreveu: "É necessário que ela seja uma projeção imediata dos humores do artista, uma projeção que nada venha falsear". Desde 1946, dizia amar "le peu", "les choses bruts", "mal façonné", "l'imparfait", "les diamants bruts, dans leur gangue" (p. 65). Ao apresentar sua coleção em Lille, em 1951, falou: "É somente nessa arte bruta que se encontram os processos naturais e normais da criação artística, em seu estado elementar e puro" (DUBUFFET, p. 106).

"Arte modesta!" - exclamou Dubuffet (1999, p. 176) - "e que muitas vezes ignora mesmo que se chama arte". Os objetos cole- 
tados eram "pinturas, desenhos, estatuetas, bordados, pequenas obras de todo o tipo, executadas à completa margem da arte cultural" (p. 109). O material deveria ser parte integrante da elaboração formal e simbólica, uma "iniciativa do material" no dizer de Thévoz (1980, p. 71), bem como o processo criativo desdobraria a invenção da própria técnica a ser utilizada. A partir daí, o artista bruto desenvolve uma linguagem plástica própria, sem referência às obras de arte oficiais, dos museus e galerias, exteriorizando seus sentimentos mais íntimos, numa invenção sem freios e reinventando as etapas do ato criador.

\section{Configuração da exposição de Arte Incomum}

Em carta dirigida aos organizadores da XVI Bienal de São Paulo, datada de 6 de julho de 1981, citada por Josette Balsa (1981, p. 48), Jean Dubuffet definia o projeto da exposição de Arte Incomum como uma "contradição" e interditava o uso da designação "arte bruta". O termo "cosmogonia" que Zanini utiliza havia aparecido na abertura de uma grande exposição dedicada aos "Singulares", ocorrida no Museu de Arte Moderna da Cidade de Paris, em 1978. A organizadora dessa mostra, Suzanne Pagé, considerava a arte desses artistas como "o vivido", portanto, uma cosmogonia. Tal ideia também aparecerá em frases de Victor Musgrave, convidado a integrar a exposição de Arte Incomum como curador internacional do módulo. Tanto pela utilização da nova terminologia quanto pelo convite feito a Musgrave, nota-se que Walter Zanini acompanhara eventos europeus mais recentes sobre o tema.

Musgrave era cineasta inglês e colecionador de arte, particularmente dedicado à Outsider Art. Junto com o crítico de arte Roger Cardinal e Alain Bourbonnais, o colecionador inglês organizou a mostra intitulada "Outsiders: an art without precedent or tradition”, na Hayward Gallery, em 1979, na qual figuravam nomes de criadores como Aloïse, Brendel, Darger, entre outros. Convém lembrar que Cardinal era estudioso da obra bruta desde o início dos anos 70 quando publicou um importante livro intitulado Outsider Art. Esta nomeação foi uma das poucas traduções admitidas por Dubuffet para sua Art Brut, passando a ser amplamente empregada.

Não apenas curador, Musgrave dispôs de parte de sua coleção pessoal para compor a representação internacional de obras do módulo de Arte Incomum. Conforme declarou numa entrevista, desde os anos 50 quando impulsionava movimentos de vanguarda, Musgrave reunira obras de camponeses, vi- 
úvas ou carteiros internados em sanatórios psiquiátricos da Europa. Sua orientação basicamente seguia os princípios de Dubuffet. O colecionador não acreditava que os desenhos expostos servissem para ilustrar casos clínicos; são obras de arte porque têm o vigor bruto: "O que distancia esses artistas do simples desenho de doente mental é a grandeza de sua imaginação" (MUSGRAVE, 1981b, p. 4). Scottie Wilson é o exemplo evocado de criador de uma cosmogonia ímpar, sem jamais ter sido internado. $\mathrm{O}$ que garantia estarmos diante de obras brutas, para Musgrave, era o fato de elas não terem sido feitas para o público, senão por compulsão e para a contemplação do próprio criador.

Nesse sentido, ele assumia a posição de crítico da historiografia da arte, dizendo na citada entrevista que "os historiadores de arte estão cegos". No prefácio da exposição brasileira, afirmou:

Procuramos apresentar uma mostra que não seja um exercício acadêmico, não tentamos articular perspectivas históricas (por não existirem) e resistimos - embora, talvez, não totalmente - à tentação de fazer comparações culturais, o que trairia o espírito da invenção 'quimicamente pura'. [...] (MUSGRAVE, 1981a, p. 14).

Para realizar a curadoria da coleção nacional de Arte Incomum, foi convidada a professora da Escola de Comunicação e Artes da Universidade de São Paulo, Annateresa Fabris. A historiadora da arte pensava a exposição a partir da memória de Flávio de Carvalho, o artista brasileiro que, em 1933, organizou a mostra pioneira de "crianças e loucos", e de Jean Dubuffet, que radicalizou mais, anulando a distinção entre o "louco" e o "são" em sua crítica à ideia de arte "anormal", interessando-se pela obra pessoal. Ao intitular seu texto para o catálogo, Fabris retoma a noção de "cosmogonia", à qual acrescenta sugestivamente a palavra "outras", em referência à necessidade de particularizar cada um dos artistas como um universo próprio, contrária, nesse caso, às classificações tradicionais da história da arte.

Observados os discursos emergentes na mostra, sobretudo em Musgrave e Fabris, nota-se o didatismo das palavras ao introduzir a nova noção, bem como ao explanar em detalhes os procedimentos de Dubuffet junto à sua Art Brut e os critérios de seleção das obras. Num depoimento de Annateresa Fabris destinado à imprensa (FABRIS, 1981b), a pesquisadora lembra que a exposição fazia apenas uma amostra primeira de Arte Incomum, "um convite à pesquisa, à reflexão, ao debate". 
A principal ênfase estava em distinguir os incomuns dos ingênuos (ou "primitivos") e da psicopatologia da arte.

Primeiramente, os nomes de Eli Heil, Poteiro e G. T. O., comumente aceitos como "primitivos", são referidos por Fabris sob a ótica proposta por Dubuffet, porque, além do autodidatismo, a pesquisadora encontrou em suas obras "a criação de mundos próprios, irredutíveis aos parâmetros tradicionais da arte" (FABRIS, 1981b). Noutra ocasião, afirmou que eles desconhecem a cultura artística, o mimetismo e a mentira cultural, para deixar vir à tona espontaneamente seus "valores selvagens"; no entanto, não devemos confundi-los com os "artistas ingênuos", porque essa arte, "apesar de ser fruto de pessoas simples, mostra respeito pela 'arte cultural', tenta imitá-la, deseja participar de seu mundo" (FABRIS, 1981a, p. 19). Musgrave (1981a, p. 12) completa dizendo que o artista ingênuo exclui-se do universo subversivo dos outsiders ao tentar ser aceito pelo mundo da arte oficial.

O segundo aspecto dizia respeito à procedência de obras de hospitais psiquiátricos, as quais deveriam, no sentido da noção dubuffetiana, afastar-se da leitura psicopatológica e da produção estrita da arte-terapia. Victor Musgrave apresentou dados da Collection de l'Art Brut de Lausanne (Suíça), onde apenas 40\% das peças eram provenientes de hospitais psiquiátricos, ao que se devem somar os vários pronunciamentos de Dubuffet contrários à identificação entre ser doente mental e ser artista. A manifestação de imagens ocultas da psique não define o criador bruto, mas o fato de sua obra ser destituída de estereótipos culturais. Também Fabris (1981a, p. 24) reiterava a improcedência de categorias psicológicas radicais: "A noção de normal e anormal desaparece diante desses universos criativos variados".

Observando em retrospectiva a história do olhar sobre as obras produzidas por aquelas pessoas economicamente pobres e esteticamente inventivas, não será outra a constatação, senão a do encontro com uma rede discursiva que distinguia "ingênuos" e "loucos". Tal distinção ocupa uma dimensão psicossocial e histórica cuja compreensão pelo pesquisador de arte é possível por meio da análise da recepção estética.

\section{A recepção da exposição de Arte Incomum na imprensa}

A contribuição da análise da recepção estética em suas condições históricas e sociais evidencia-se pelo exame das fontes impressas divulgadas a partir daquela mostra. Sobre a difenças entre "primitivos", ingênuos" e "incomuns", o jornalista 
Fernando Lemos (1981a, p. 54) comentou: "Seria "incomum" aquilo que Osório Cesar chamava a "arte primitiva dos alienados"? Ou seria - o que na essência diz a mesma coisa - a arte psicopatológica, muito ao gosto dos surrealistas...."

Se as obras expostas se limitassem aos ateliês psiquiátricos, pondera o jornalista, a Arte Incomum seria compreensível pela via aberta por Osório Cesar como "arte psicopatológica". No entanto, esse caminho está descartado pela presença de "primitivos", fato que o conduz a nova indagação: "G. T. O., Poteiro e Heil se tornam artificialmente 'incomuns' para obter os valores que aqueles, que por serem 'incomuns' (artistas do Museu de Imagens do Inconsciente e do Juquery), alcançaram?".

Em outro texto jornalístico, Alberto Beuttenmuller (1981) afirmou: "Colocar Eli Heil, Poteiro e G. T. O. junto aos hóspedes de hospitais psiquiátricos é, no mínimo, uma temeridade". Conclui que "a chamada arte primitiva é a mesma coisa, e a confusão é maior, pois tais características se ajustam a ambas as classificações": "Para toda a crítica nacional, é uma temeridade confundir Geraldo Telles de Oliveira - o G. T. O. - Eli Heil e Antonio Poteiro [...] com a arte realizada por esquizofrênicos e paranóicos dos sanatórios psiquiátricos, ali representados".

O núcleo da discussão diz respeito ao espaço no interior do qual a obra bruta foi elaborada. A proveniência do hospital conferia às obras de seus internos um status indesejável que as acompanhava. A dificuldade estava em deslindar-se a dicotomia entre "ingênuos" e "loucos", cujo resultado era a impossibilidade de conceber o valor artístico da obra de criadores populares cuja extrema expressão seria indicativa de loucura.

A divulgação na imprensa evidencia a contradição do que se pretendia com a Arte Incomum: se, por um lado, os organizadores afastavam a noção do campo da psicopatologia, por outro, repórteres e mesmo pessoas mais envolvidas com a organização reuniam os dois campos. Um exemplo disso é a conversa de Leonor Amarante (1981b) com Paulo Fraletti, psiquiatra que havia contribuído com o empréstimo de obras para a composição do módulo, na qual o médico reafirma seu vínculo estreito com Osório Cesar e o ateliê do Hospital de Juquery, fechado em 1973 com a transferência de Fraletti para São Paulo. O conteúdo da entrevista basicamente retoma ideias do psiquiatra quando comparou a arte dos alienados com a de crianças, "primitivos" e artistas modernos (FRALETTI, 1954). Amarante (1981b) acaba por indagar: "Repetindo o feito pela II Bienal de São Paulo, em 1953, a arte dos psicopatas volta ao Pavilhão do Ibirapuera para reabrir a questão. Arte ou loucura?" 
Outros exemplos extraídos da imprensa diária poderiam mostrar o enlace indissolúvel da Arte Incomum com as ideias psicopatológicas, como a reportagem convidando à exposição em que figuravam "desenhos de loucos, esquizofrênicos, pacientes psiquiátricos, colocados lado a lado com alguns artistas de exceção" (PEREIRA, 1981). Tal problemática remonta ao final dos anos 40, quando despontaram as primeiras exposições de artistas internados, enredando-os na figura equívoca do "artista psicótico", notável no famoso debate entre Mário Pedrosa e Quirino Campofiorito (SILVEIRA, 1966).

O jornalista Cerqueira Lemos (1981b) questionou as intenções dos organizadores da mostra, e mesmo as de Dubuffet, em desvincular as obras expostas da loucura de seus criadores. Procurando concentrar a discussão na obra, em vez de no artista - se louco ou não, se iletrado ou não -, considera ser "incomum" "um departamento exclusivo dos desajustados mentais".

A dificuldade de compreensão da ideia de uma Arte Incomum não estava apenas baseada na imprensa que a recebeu em primeira mão, mas na sua própria constituição na Bienal de São Paulo, evidenciando uma contradição essencial entre a coleção internacional de Art Brut e a coleção brasileira de Arte Incomum. Lemos (1981b) observou: "Victor Musgrave apontou-me Antonio Poteiro como 'folclore'. E outros como 'primitivos', simplesmente”. Mas Fabris (1981a) registrara serem todos os três exemplos de uma visão peculiar de mundo, como propugnava Dubuffet.

\section{Conclusão}

As primeiras recepções da Art Brut foram marcadas por críticas, mas também por interesse (PEIRY, 1997, p. 82); uns encontraram ali reminiscências da arte russa medieval, pré-colombiana, outros um ar fresco na cultura. A recepção estética da exposição de Arte Incomum foi estudada de modo fundamental por João Frayze-Pereira (1995). Sua pesquisa junto ao público permitiu constatar a emergência de temas românticos nas palavras de muitos espectadores, num acolhimento positivo das obras expostas, ainda que declaradamente com estranheza e espanto. Afirmou Frayze-Pereira (1995, p. 139): "No face a face com as obras os leitores contemplam a origem que se perdeu, o mito que a sociedade não oferece mais e que a extrema racionalidade tecnocrática faz perder cada vez mais." Um dos fundadores da Estética da Recepção, Hans Jauss (1978), dizia que não se pode resgatar dos fenômenos ar- 
tísticos nenhuma ligação objetiva entre as obras que não seja estabelecida pelos sujeitos da produção e da recepção, ou seja, há um "caráter intersubjetivo" da sua continuidade e definidor de seu destino.

Desde a década de 1950, desenvolveram-se estudos de psicologia social da percepção. Hungerland (1954) observou essas pesquisas para averiguar a contribuição específica para a percepção das obras de arte, concluindo que há uma relação importante com a crítica de arte. Na França, a sociologia da recepção tem procurado circunscrever os instrumentos de percepção da obra de arte, a exemplo de Bourdieu e Darbel (1969) e Nathalie Heinich (2002). Nesses dois estudos, a estrutura social organiza a percepção, mas o faz em relação à história, ou seja, ao processo de duração das formas de perceber conforme determinadas categorias de julgamentos artísticos. Nesse sentido, Junod (1986, p. 280) afirmou que o problema se inscreve em "um espaço sociocultural e no tempo da história". Em Bourdieu (1968, p. 649) "o olho é histórico" e a obra de arte é feita pelo menos duas vezes, uma pelo artista e outra pelo público.

Em síntese, entre o público e a obra de arte funda-se um campo intersubjetivo formado por discursos e imagens representativos de tempos históricos distintos; as mediações na recepção de tais obras possuem, na mesma medida, temporalidades diversas. Além daqueles temas românticos, cuja historicidade recoloca o imaginário oitocentista, a pesquisa de fontes impressas contemporâneas à exposição de Arte Incomum evidencia os conflitos sociais provocados pelo ingresso dos criadores provenientes das classes populares no campo artístico durante o século XX. Trata-se de um problema cuja essência é a duração de julgamentos artísticos no interior do campo artístico.

Se, por um lado, a recepção de uma Arte Incomum não se sustentava, porque o campo das obras de criadores populares cindira-se em duas partes determinadas pelas categorias de naïfse de "psicóticos", por outro lado, essas duas noções preexistentes abrigavam uma contradição ainda mais complicada que o novo conceito pudesse suplantar. Tanto a categoria de "arte ingênua" como a de "arte psicopatológica" se constituíram a partir de dois olhares distintos, ambos fundados numa competência exterior aos processos próprios da criação plástica das pessoas de classes populares. Tal distinção, partilhada entre a psiquiatria e a crítica de arte, forjava dois pólos de drama e gozo, os quais estariam projetados respectivamente 
em artistas "psicóticos" e "ingênuos". Uma pesquisa sobre a produção dita "ingênua" nos ateliês dos hospitais psiquiátricos notou que a instituição psiquiátrica não encerra o drama psíquico, da mesma maneira que a prática pictórica ingênua não o ausenta (ANDRIOLO, 2006).

O exame da recepção da exposição, notadamente na imprensa, mostra que a rede discursiva sobre a qual se inscreveram as obras não concebia a terceira via aberta pela Arte Incomum, como também não aceitara a noção de Arte Virgem, proposta por Pedrosa (1950). Criadores como Adelina, Aurora, Poteiro, Emygdio, Fernando, Eli Heil, G. T. O., Gabriel dos Santos, entre outros, poderiam não enquadrar-se na ortodoxia dubuffetiana, mas Annateresa Fabris (1981a, p. 24) não se enganava ao encontrar em todos esses artistas "visões particulares" altamente pessoais, sem parentesco com estilos e categorias preconcebidas, "um mundo próprio, uma linguagem própria, buscada nas forças mais secretas do ser". Elas são visões fabuladas. No jogo social que define as categorias da percepção das obras de arte, ao lado de formas dominantes de perceber, organizam-se outras cuja duração dependerá de uma série de fatores interiores e exteriores ao campo artístico. Por exemplo, Fabuloserie - o lugar das fábulas - era o nome de uma coleção dissidente da concepção dubuffetiana nos anos 70, organizada por Alain Bourbonnais e defendida ardorosamente por Michel Ragon (1983). Uma proposta mais ampla que a de Art Brut, ao mesmo tempo em que distante das categorias psiquiátricas. Também é forçoso reiterar o projeto original de Mário Pedrosa (1994) para um Museu de Arte Virgem, fomentado desde os anos 1950, no qual os artistas tornariam real o imaginado, instaurando suas visões de mundo; no dizer desse crítico, são eles que preparam o cotidiano para uma nova mitologia, dando a fabulação que faltava aos lugares comuns.

\section{Referências Bibliográficas}

AMARANTE, Leonor. A Bienal procura novos caminhos. $O$ Estado de S. Paulo, São Paulo, 19 jul. 1981a, p. 39.

AMARANTE, Leonor. Os limites da arte "incomum" na XVI Bienal. O Estado de S. Paulo, 20 set. 1981b. (recorte sem número de pág. Acervo Fundação Bienal de São Paulo)

ANDRIOLO, Arley. O silêncio da "pintura ingênua" no ateliê psiquiátrico. Psicologia: Teoria e Pesquisa, Brasília, v. 22, n. 2, 2006, p. 227-232.

BALSA, Josette. A arte é um antidestino. Arte Incomum. XVI 
Bienal de São Paulo, 16 out. a 20 dez. 1981, p. 48.

BEUTTENMULLER, Alberto. XVI Bienal de São Paulo - poucas atrações e a arte "naïf" com outro nome. Jornal do Brasil, Rio de Janeiro, 3 out. 1981. (recorte sem número de pág. Acervo Fundação Bienal de São Paulo)

BOURDIEU, Pierre \& DARBEL, Alain. L'amour de l'art, les musées d'art européens et leur public. Paris: Ed. Minuit. Ed. Ampliada, 1969.

BOURDIEU, Pierre. Éléments d'une théorie sociologique de la perception artistique. Revue Internationale des Sciences Sociales, Unesco, Paris, vol. 20, n. 4, 1968, p. 640-664.

DUBUFFET, Jean. L'homme du commun à l'ouvrage. Paris: Gallimard, 1999.

DUBUFFET, Jean. Préface. L’Art Brut, fascicule 1, Paris, 1964, p. 3-5.

FABRIS, Annateresa. "Arte Incomum”, Depoimento de Annateresa Fabris, texto mimeografado, 2 fls. Timbre Fundação Bienal de São Paulo, 1981b.

FABRIS, Annateresa. Cosmogonias outras. In: Arte Incomum. XVI Bienal de São Paulo, 16 out. a 20 dez. 1981a, p. 19-25.

FRALETTI, Paulo. Considerações sobre a arte dos alienados e dos artistas modernos. Arquivos do Departamento de Assistência a Psicopatas do Estado de São Paulo, vol. XX, n. 3-4, jul.-dez. 1954, p. 139-173.

FRAYZE-PEREIRA, João. Olho D'Água: arte e loucura em exposição. São Paulo: Escuta, 1995.

HEINICH, Nathalie. Le rejet de l'art contemporain, pourquoi? Sciences Humaines, hors-série, n. 37, juin-jullet-août, 2002, p. 56-59.

HUNGERLAND, Helmut. An analysis of some determinants in the perception of the works of art. The Journal of Aesthetics $\mathcal{E}$ Art Criticism, vol. 12, n. 4, june. 1954, p. 450-456.

JAUSS, Hans Robert. Histoire et histoire de l'art. In: Pour une esthétique de la réception. Prefácio Jean Starobinski. Paris: Gallimard, 1978, p. 81-122.

JUNOD, Philipe. La perception esthétique comme variable historique. In: MOULIN, R. (dir.) Sociologie de l'Art. Colloque international, Mareseille, 13-14 juin, 1985. Paris: La Documentation Française, 1986, p. 279-284.

LEMOS, Fernando Cerqueira. Primitivo, ingênuo e incomum. Folha de S. Paulo, $5{ }^{\circ}$ Caderno - Ilustrada, 13 set. 1981a, p. 54.

LEMOS, Fernando Cerqueira. $\mathrm{O}$ incomum continente primitivo. Folha de S. Paulo, 13 dez. 1981b. (recorte sem número 
de pág. Acervo Fundação Bienal de São Paulo)

MUSGRAVE, Victor. A bela arte dos loucos. [18 nov. 1981 b ]. São Paulo: Veja, pp. 6-8. Entrevista concedia a Casimiro Xavier de Mendonça.

MUSGRAVE, Victor. Apresentação. In: Arte Incomum. XVI Bienal de São Paulo, 16 out. a 20 dez. 1981a, p. 11-14.

Novidade na XVI Bienal: ordenação crítica. Projeto, set. 1981, p. 10.

PEDROSA, Mário. Emygdio. In: FUNARTE/IBAC. Coordenação de Artes Visuais. Museu de Imagens do Inconsciente. 2 ed. Rio de Janeiro: FUNARTE/Ed. UFRJ, 1994, p. 62-74.

PEDROSA, Mário. Pintores da arte virgem. In: Dimensões da arte. Rio de Janeiro: Ministério da Educação e Cultura, 1964, p. 105-115. (edição original jan. 1950)

PEIRY, Lucienne. L’Art Brut. Paris: Flamarion, 1997.

PEREIRA, José Mário. A arte livre representada nas imagens do inconsciente. Última Hora, Rio de Janeiro, 26 out. 1981. (recorte sem número de pág. Acervo Fundação Bienal de São Paulo)

RAGON, Michel. Préface. In: BOURBONNAIS, Alain (org.). La Fabuloserie (La): art hors les normes, art brut (Dicy Yonne). Paris: SMI, 1983, p. 1-15.

SILVEIRA, Nise da. 20 anos de terapêutica ocupacional em Engenho de Dentro. Revista Brasileira de Saúde Mental, Rio de Janeiro, v. 10, n. único, 1966.

Singuliers de l'Art (Les). Exposition e catalogue par l'ARC avec Suzanne Pagé, Musée d'Art Moderne de la Ville de Paris, 19 jan. a 5 mar., 1978.

THÉVOZ, Michel. L'Art Brut. Genève: Editions d'Art Albert Skira, 1980.

ZANINI, Walter. A Bienal e os artistas incomuns. In: Arte Incomum. XVI Bienal de São Paulo, 16 out. a 20 dez. 1981, p. 7-8.

Recebido em: 02/o8/10

Aceito em: 29/10/10 


\section{ARLEY ANDRIOLO \\ a.a.andriolo@gmail.com \\ É bacharel em História, doutor em Psicologia Social pela Universidade de São Paulo, docente junto ao Departamento de Psicologia Social e do Trabalho do Instituto de Psicologia da Universidade de São Paulo. Coordenador do Laboratório de Estudos em Psicologia da Arte do mesmo Instituto. A pesquisa aqui apresentada contou com o apoio da FAPESP.}

